\title{
Closing the gap between knowing and causing the Anthropocene
}

\author{
This article belongs to Ambio's 50th Anniversary Collection. Theme: Anthropocene
}

\author{
Wiebren J. Boonstra
}

In this 50th Anniversary Collection, Ambio presents and discusses articles that importantly contributed to understanding the historical causes and development of the Anthropocene (Folke et al. 2002; Liu et al. 2007; Steffen et al. 2007, 2011). The Anthropocene denotes the current geological age, viewed as a period during which human activity started to fundamentally alter the synergetic dynamics of climatological, geological and biological processes on Earth (Pálsson 2020, p. 10).

Parallel to any indicator that measures the impact of human life on Earth (see Steffen et al. 2007, p. 617), the prevalence of the term Anthropocene in the human written record grows ferociously (Fig. 1). Except the popularity of the term lags 60 odd years behind the reality it describes. As if the epistemology of the Anthropocene is trying to catch up with its ontology. ${ }^{1}$

The authors of the four Ambio articles that feature in this anniversary collection have written personal reflections about the origins of their work and its impact on science and society (Folke et al. 2021; Liu et al. 2021; Steffen 2021). Included as well are the contributions of two academic peers who place these articles in the growing, heated, and interdisciplinary debate about the Anthropocene as reality and idea (Castree 2021; O'Brien 2021).

Reading the four articles again, I found it striking how they together exemplify a leading scientific perspective on the history of global social-ecological interactions. Central to this perspective is the conviction that human societies are interdependent with natural environments as "systems" (Folke et al. 2002, p. 437); an expansion of this socialecological interdependency to encompass the whole planet, or-to keep with the discourse- "Earth system" (Liu et al. 2007 , p. 645); and an appeal to humanity to take responsibility for this system through "planetary" or "earth stewardship" (Steffen et al. 2011, p. 749-757).
The peer reflections discuss why and how this perspective has progressed our understanding of the history of socialecological interactions, but also why their framing of the impact of human society on Earth triggered debate (Castree 2021; O'Brien 2021). This debate concerns, amongst other things, the appeal to humanity at large (cf. the calls for Earth stewardship) to redress their impact on nature. The peer reflections also notice that a gap persists to this day between knowing and causing the Anthropocene-the evidence for the risks that come from the expansion of human society on planet Earth is abundant, but people and societies fail to take precautionary actions based on this knowledge. One of the authors of the four articles, Will Steffen soberly concludes in his personal reflection that the caution his work raised "has fallen on deaf ears", and suggests that we now need solutions "rather than yet another diagnosis of the problem" (Steffen 2021; see also Ripple et al. 2017).

Considering the knowledge and debate about the Anthropocene, and the immediate signs of the climate emergency that we are facing what are the solutions? What are the "deep transformations" (O'Brien 2021) that so many scientists, students, and others ask for and how can these be realized? I hope that the articles included in this 50th Anniversary Collection on the Anthropocene might contribute to the solution-oriented science that Steffen advocates. ${ }^{2}$ I will conclude this introduction in the same spirit that marks these articles that follow by offering some

\footnotetext{
${ }^{1}$ Ontology is a theory about reality or the nature of being. Epistemology is a theory about what and how we can know this reality, i.e. a theory of knowledge and understanding, especially with regard to its methods, validity, and scope, and the distinction between justified belief and opinion (Oxford English Dictionary 2020).

${ }^{2}$ See also our final 50th anniversary collection which focusses on solution-oriented research.
} 


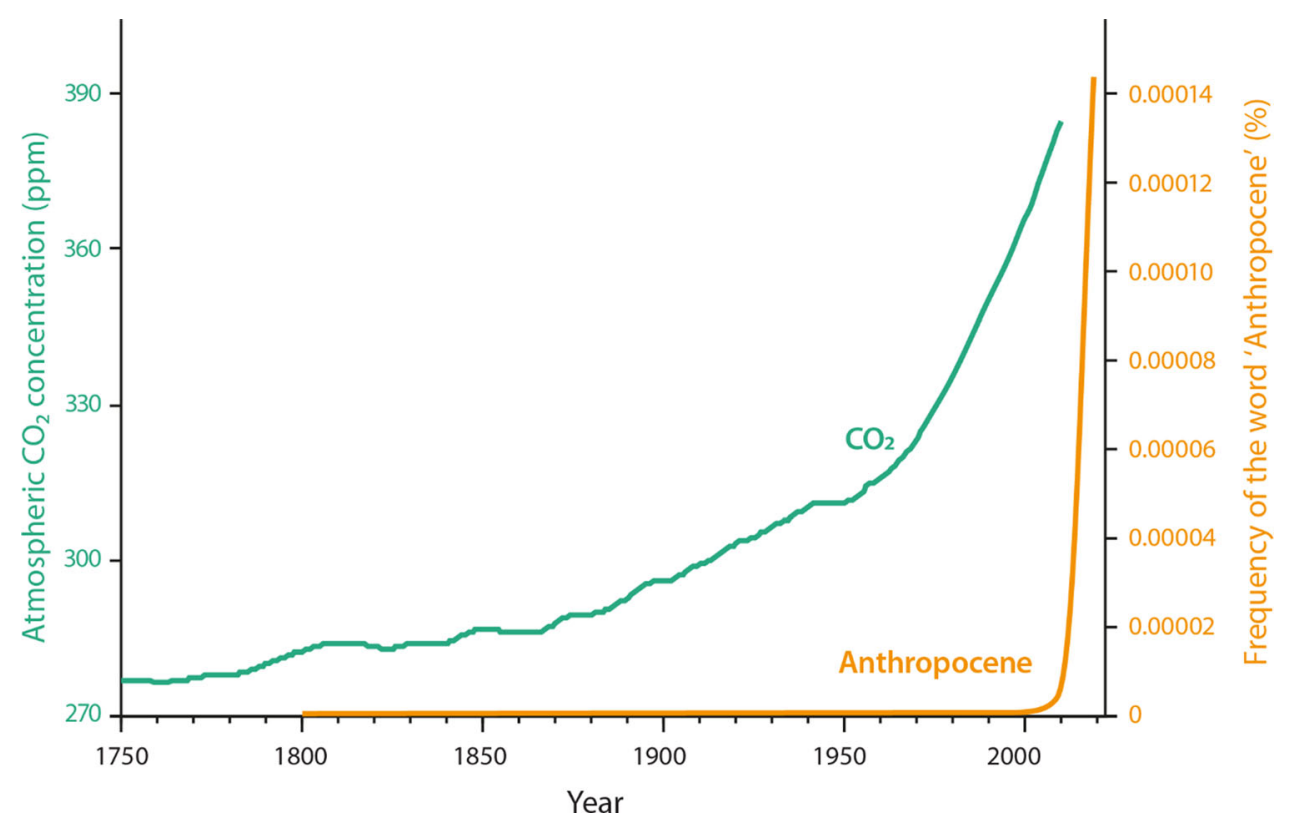

Fig. 1 The global increase of atmospheric $\mathrm{CO}_{2}$ concentration (derived from Steffen et al. 2007, p. 617) compared to the increase in the use of the word 'Anthropocene' in Google's text corpora (https://books.google.com/ngrams/)

personal reflections on what might close the gap between knowing and causing the Anthropocene.

The history of the Anthropocene demonstrates that humans transformed their relation with nature, others and themselves whenever they learned and got used to wielding new sources of energy during the domestication of fire, agrarianization, and industrialization. Until now these transformations occurred for the most part as unplanned changes and have only expanded the "the anthroposphere" (Goudsblom 2002, p. 24) in the biosphere to the extent that it is now crowding out non-human forms of life.

The deep transformation that is required to remain safely within planetary boundaries would, in my view, have to break with the historical trend of expansion. For this to happen we need to become much more savvy about the mechanisms and dynamics through which human societies grow, and acknowledge that expansion of the anthroposphere threatens human existence in the Biosphere. Growth of material throughput needs to be recognized and condemned as an inherently dangerous feature of our societies. The detrimental dream of perpetual economic growth as guiding principle for human development needs to be replaced by a focus on how to prosperously compress and degrow the Anthroposphere (cf. Odum and Odum 2008; Raworth 2017; Parrique 2019).

Attention to power and inequality is indispensable. Not all humans expand the anthroposphere to the same degree (Boonstra 2016). The richest $10 \%$ of the world population, for example, emit more than $50 \%$ of the global carbon emissions since $1990 .^{3}$ Also, unequal, meritocratic societies tend to cause more environmental harm due to their excessive stimulation of economic growth (Wilkinson and Pickett 2010; Sayer 2015; Sandel 2020).

A compression of the anthroposphere by managing the size and extensiveness of human activity and enterprise (Sale 2017) might facilitate the type of responsibility that Will Steffen and other contributors to this issue wish for. We have to feel the Anthropocene before we can take responsibility for causing it (Morton 2013, p. 1-2; Purdy 2015 , p. 4; ten Bos 2017, p. 72). Feelings of responsibility flow habitually to things or beings close to us- the environments and groups in which we live our everyday lives (de Swaan 1995, p. 26) - and less readily to the planet at large (Smith 1759 [2000], p. 192-194). Stewardship works in a small anthroposphere.

Recipes of smarter technology, global institutions, and more adaptive management have so far not closed the gap between knowing and causing the Anthropocene. It is time for something else. An anthroposphere with less stuff and less billionaires by redressing its scale deserves wider attention as possible solution for human wellbeing on Earth.

\footnotetext{
${ }^{3}$ See Jason Hickel's article in The Correspondent "We can't have billionaires and stop climate change" [https://thecorrespondent.com/ 728/we-cant-have-billionaires-and-stop-climate-change/77418988847 $2-6 c 76 d 394$ ?pk_campaign $=$ daily $\&$ mc_cid $=$ deea $337023 \&$ mc_eid $=31 \mathrm{f}$ 8fe9fa7]; as well as Oxfam's 2020 study "Confronting carbon inequality" [https://oxfamilibrary.openrepository.com/bitstream/handle/ 10546/621052/mb-confronting-carbon-inequality-210920-en.pdf].
} 
Acknowledgements I would like to thank Bo Söderström, Erik Andersson and Sofie Joosse for helpful comments and suggestions related to earlier versions of this editorial.

\section{REFERENCES}

Boonstra, W.J. 2016. Conceptualizing power to study social-ecological interactions. Ecology and Society 21: 21. https://doi.org/10. 5751/ES-07966-210121.

Castree, N. 2021. Framing, de-framing and reframing the Anthropocene. 50th Anniversary Collection: Anthropocene. Ambio, Volume 50. https://doi.org/10.1007/s13280-020-01437-2.

de Swaan, A. 1995. Widening circles of identification: Emotional concerns in sociogenetic perspective. Theory, Culture \& Society 12: $25-39$.

Folke, C., S. Carpenter, T. Elmqvist, L. Gunderson, and B. Walker. 2021. Resilience: Now more than ever. 50th Anniversary Collection: Anthropocene. Ambio, Volume 50. https://doi.org/ 10.1007/s13280-020-01487-6.

Folke, C., S. Carpenter, T. Elmqvist, L. Gunderson, C.S. Holling, and B. Walker. 2002. Resilience and sustainable development: Building adaptive capacity in a world of transformations. Ambio 31: 437-440. https://doi.org/10.1579/0044-7447-31.5.437.

Goudsblom, J. 2002. Introductory overview: The expanding anthroposphere. In Mappae Mundi. Humans and their habitats in a long-term socio-ecological perspective, ed. B. de Vries and J. Goudsblom, 21-46. Amsterdam: Amsterdam University Press.

Liu, J., T. Dietz, S.R. Carpenter, W.W. Taylor, M. Alberti, P. Deadman, C. Redman, A. Pell, et al. 2021. Coupled Human and ${ }^{a} \mathrm{~d}$ applications of an integrated framework. 50th Anniversary Collection: Anthropocene. Ambio, Volume 50. https://doi.org/10. 1007/s13280-020-01488-5.

Liu, J., T. Dietz, S.R. Carpenter, C. Folke, M. Alberti, C.L. Redman, S.H. Schneider, E. Ostrom, et al. 2007. Coupled human and natural systems. Ambio 36: 639-649. https://doi.org/10.1579/ 0044-7447(2007)36[639:CHANS]2.0.CO;2.

Morton, T. 2013. Hyperobjects. Philosophy and ecology after the end of the world. Minnesota: University of Minnesota Press.

O'Brien, K. 2021. Reflecting on the Anthropocene: The call for deeper transformations. 50th Anniversary Collection: Anthropocene. Ambio, Volume 50. https://doi.org/10.1007/s13280-02001468-9.

Odum, H.T., and E.C. Odum. 2008. A prosperous way down: Principles and policies. Denver: University Press of Colorado.
Pálsson, G. 2020. The human age: How we created the Anthropocene epoch and caused the climate crisis. London: Welbeck.

Parrique, T. 2019. The political economy of degrowth. $\mathrm{PhD}$ thesis. Clermont-Ferrand: University of Clermont Auvergne.

Purdy, J. 2015. After nature: A politics for the Anthropocene. Harvard: Harvard University Press.

Raworth, K. 2017. A doughnut for the Anthropocene: Humanity's compass in the 21st century. The Lancet Planetary Health 1: e48-e49.

Ripple, W.J., C. Wolf, T.M. Newsome, M. Galetti, M. Alamgir, E. Crist, and 15364 Scientist Signatories from 184 Countries. 2017. World scientists' warning to humanity: A second notice. BioScience 67: 1026-1028.

Sale, K. 2017. Human scale revisited: A new look at the classic case for a decentralist future. White River Junction: Chelsea Green Publishing.

Sandel, M.J. 2020. The tyranny of merit. What's become of the common good?. New York: Allen Lane.

Sayer, A. 2015. Why we can't afford the rich. Bristol: The Policy Press.

Smith, A. 1759 [2000]. The theory of moral sentiments. New York: Prometheus Books.

Steffen, W. 2021. Introducing the Anthropocene: The human epoch. 50th Anniversary Collection: Anthropocene. Ambio, Volume 50. https://doi.org/10.1007/s13280-020-01489-4.

Steffen, W., P.J. Crutzen, and J.R. McNeil. 2007. The Anthropocene: Are humans now overwhelming the great forces of nature? Ambio 36: 614-621. https://doi.org/10.1579/00447447(2007)36[614:taahno]2.0.co;2

Steffen, W., Å. Persson, L. Deutsch, J. Zalasiewicz, M. Williams, K. Richardson, C. Crumley, P. Crutzen, et al. 2011. The Anthropocene: From global change to planetary stewardship. Ambio 40: 739-761. https://doi.org/10.1007/s13280-011-0185-x.

ten Bos, R. 2017. Dwalen in het Antropoceen [Wandering in the Anthropocene]. Meppel: Boom.

Wilkinson, R., and K. Pickett. 2010. The spirit level: Why equality is better for everyone. London: Penguin.

Publisher's Note Springer Nature remains neutral with regard to jurisdictional claims in published maps and institutional affiliations.

\section{Wiebren J. Boonstra $(\square)$}

Address: Natural Resources and Sustainable Development, Department of Earth Sciences, Uppsala University, Uppsala, Sweden.

e-mail: wijnand.boonstra@geo.uu.se 


\section{Resilience and Sustainable Development: Building Adaptive Capacity in a World of Transformations}

Emerging recognition of two fundamental errors underpinning past polices for natural resource issues heralds awareness of the need for a worldwide fundamental change in thinking and in practice of environmental management. The first error has been an implicit assumption that ecosystem responses to human use are linear, predictable and controllable. The second has been an assumption that human and natural systems can be treated independently. However, evidence that has been accumulating in diverse regions all over the world suggests that natural and social systems behave in nonlinear ways, exhibit marked thresholds in their dynamics, and that social-ecological systems act as strongly coupled, complex and evolving integrated systems. This article is a summary of a report prepared on behalf of the Environmental Advisory Council to the Swedish Government, as input to the process of the World Summit on Sustainable Development (WSSD) in Johannesburg, South Africa in 26 August 4 September 2002. We use the concept of resilience-the capacity to buffer change, learn and developas a framework for understanding how to sustain and enhance adaptive capacity in a complex world of rapid transformations. Two useful tools for resilience-building in social-ecological systems are structured scenarios and active adaptive management. These tools require and facilitate a social context with flexible and open institutions and multi-level governance systems that allow for learning and increase adaptive capacity without foreclosing future development options.
The goal of sustainable development is to create and maintain prosperous social, economic, and ecological systems. These systems are intimately linked: humanity depends on services of ecosystems for its wealth and security. Moreover, hum ans can transform ecosystems into more or less desirable conditions. Hum anity receives many ecosystem services, such as clean water and air, food production, fuel, and others. Yet human action can render ecosystems unable to provide these services, with consequences for human livelihoods, vulnerability, and security. Such negative shifts represent loss of resilience.

New insights have been gained during the last 10 years about the essential role of resilience for a prosperous development of society (1). A growing number of case studies have revealed the tight connection between resilience, diversity and sustainability of social-ecological systems $(2,3)$. This article is a summary of a major report prepared on behalf of the Environmental Advisory Council to the Swedish Government, as input to the process of the World Summit on Sustainable Development (WSSD) in Johannesburg, South Africa in August 2002 (4). In the report, we provide an up-to-date synthesis of case studies and recent insights, in the context of emerging theories of complex systems characterized by uncertainty and surprise (5-7).

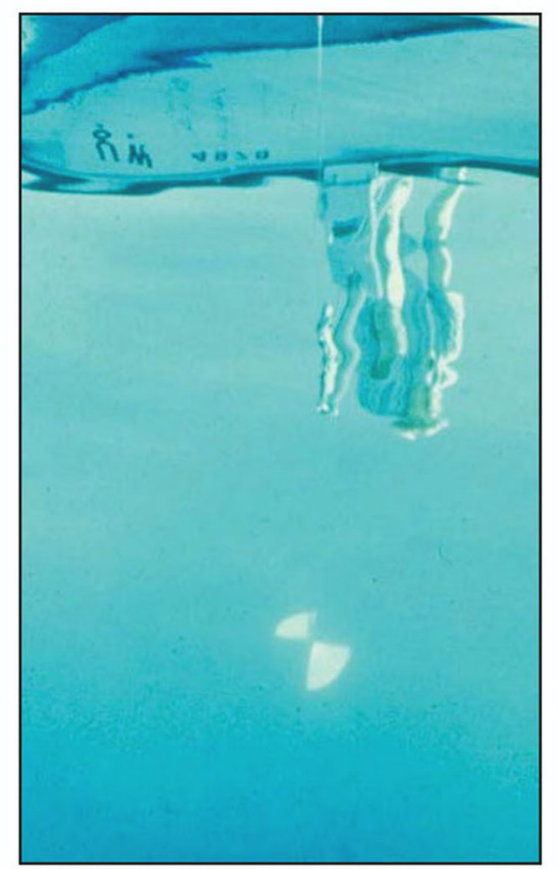

Lakes can exist with clear water providing many ecosystem services, or turbid water with toxic algae blooms. Either state can be resilient dependent upon management. Photos: S. Carpenter. 
Article Jianguo Liu, Thomas Dietz, Stephen R. Carpenter, Carl Folke, Marina Alberti, Charles L. Redman, Stephen H. Schneider, Elinor Ostrom, Alice N. Pell, Jane Lubchenco, William W. Taylor, Zhiyun Ouyang, Peter Deadman, Timothy Kratz and William Provencher

\section{Coupled Human and Natural Systems}

Humans have continuously interacted with natura systems, resulting in the formation and development of coupled human and natural systems (CHANS). Recent studies reveal the complexity of organizational, spatial, and temporal couplings of CHANS. These couplings have evolved from direct to more indirect interactions, from adjacent to more distant linkages, from local to global scales, and from simple to complex patterns and processes. Untangling complexities, such as reciprocal effects and emergent properties, can lead to nove scientific discoveries and is essential to developing effective policies for ecological and socioeconomic sustainability. Opportunities for truly integrating various disciplines are emerging to address fundamental questions about CHANS and meet society's unprecedented challenges.

\section{INTRODUCTION}

Coupled human and natural systems (CHANS) are systems in which human and natural components interact. Although humans have interacted with the biophysical environment since the beginning of human history, the scope and intensity of these interactions have increased dramatically since the Industrial Revolution. Historically, most human-nature interactions took place at the local scale, although there were some large-scale human migrations and other broad activities, such as trade and wars. Today, interactions between human and natural systems at the regional, continental, and global scales have emerged as special concerns because human activities are globally connected.

Although human-nature interactions have long been recognized (1-9), the complex patterns and processes involved in such interactions have not been well characterized, let alone fully understood $(10,11)$. Traditional research in the social and natural sciences informs the current interest in CHANS. However, social scientists have often focused on human interactions, minimizing the role of environmental context or perceiving environmental influences to be constant, whereas ecologists have traditionally focused on pristine environments in which humans are external and rarely dominant agents. Although disciplinary research continues to be important to advance disciplinary inquiries into many aspects of human and natural systems, it is not effective to study human and natural systems separately when addressing social-ecological and human-environment interactions (12-16).

The importance of developing a new integrated framework to study CHANS is recognized in a growing set of interdisciplinary research programs (see examples in Table 1). These projects go well beyond what was commonplace in ecological and social sciences research just a decade or two ago. The human and natural domains are no longer viewed as separate but rather as connected and embedded entities in webs of interactions. For instance, the Millennium Ecosystem Assessment (17) explicitly integrated social and ecological systems by analyzing the global status, trends, and future scenarios of 24 selected ecosystem services and more than 70 policy instruments for addressing them. Results from CHANS research have been published in various outlets, and a few interdisciplinary journals, such as Ambio, have been unusually receptive to such findings $(18-21)$.

The science of CHANS builds on but moves beyond previous work (e.g., human ecology, ecological anthropology, environmental geography). First, CHANS research focuses on the patterns and processes that link human and natural systems. Second, CHANS research, such as integrated assessment of climate change (22), emphasizes reciprocal interactions and feedbacks-both the effects of humans on the environment and the effects of the environment on humans. Third, understanding within-scale and cross-scale interactions between human and natural components (e.g., how large-scale phenomena emerge from local interactions of multiple agents and in turn influence local systems) is a major challenge for the science of CHANS. Although each of these three aspects has been addressed in some studies on human-environment interactions $(23,24)$, the science of CHANS promotes the integration of all these aspects. Such integration is needed to tackle the increased complexity and to help prevent the dreadful consequences that may occur due to the fundamentally new and rapid changes, because the magnitude, extent, and rate of changes in human-natural couplings have been unprecedented in the past several decades, and the accelerating human impacts on natural systems may lead to degradation and collapse of natural systems which in turn compromise the adaptive capacity of human systems. Constructing approaches that emphasize an integrative framework and comprehensive methods for understanding complexities of human-nature interactions is an urgent and growing priority $(10,24-28)$ (Table 1$)$.

In this article, we synthesize major characteristics of complex organizational couplings (among organizational levels), spatial couplings (across space), and temporal couplings (over time) of CHANS. To demonstrate practical values of studying these complex characteristics, we discuss their implications for sustainable environmental/natural resource management and governance. To guide future research efforts, this article illustrates several main opportunities and challenges in studying CHANS. Although some discussion in this article is brief due to space limitation and some issues in this article have been discussed in other contexts, integrating all relevant important topics in one article provides a holistic view of the relationships among CHANS complexities, implications, and prospects.

\section{ORGANIZATIONAL COUPLINGS}

\section{Reciprocal Effects and Feedbacks}

Coupled human and natural systems can be conceptualized as entities with nested hierarchies $(15,29)$. In CHANS, people and nature interact reciprocally across diverse organizational levels (30). They form complex webs of interaction that are embedded in each other.

Humans depend on nature for a wide array of ecosystem services $(31,32)$, including potable water, clean air, nutritious food, raw materials, and medicine. Many aspects and processes of nature upon which humans depend, however, are threatened or have disappeared due to human action or inaction (17). For example, humans have significantly altered between one-third 


\section{The Anthropocene: Are Humans Now Overwhelming the Great Forces of Nature?}

\begin{abstract}
We explore the development of the Anthropocene, the current epoch in which humans and our societies have become a global geophysical force. The Anthropocene began around 1800 with the onset of industrialization, the central feature of which was the enormous expansion in the use of fossil fuels. We use atmospheric carbon dioxide concentration as a single, simple indicator to track the progression of the Anthropocene. From a preindustrial value of 270-275 ppm, atmospheric carbon dioxide had risen to about $310 \mathrm{ppm}$ by 1950 . Since then the human enterprise has experienced a remarkable explosion, the Great Acceleration, with significant consequences for Earth System functioning. Atmospheric $\mathrm{CO}_{2}$ concentration has risen from 310 to $380 \mathrm{ppm}$ since 1950 , with about half of the total rise since the preindustrial era occurring in just the last 30 years. The Great Acceleration is reaching criticality. Whatever unfolds, the next few decades will surely be a tipping point in the evolution of the Anthropocene.
\end{abstract}

\section{INTRODUCTION}

Global warming and many other human-driven changes to the environment are raising concerns about the future of Earth's environment and its ability to provide the services required to maintain viable human civilizations. The consequences of this unintended experiment of humankind on its own life support system are hotly debated, but worst-case scenarios paint a gloomy picture for the future of contemporary societies.

Underlying global change (Box 1) are human-driven alterations of $i$ ) the biological fabric of the Earth; ii) the stocks and flows of major elements in the planetary machinery such as nitrogen, carbon, phosphorus, and silicon; and iii) the energy balance at the Earth's surface (2). The term Anthropocene (Box 2) suggests that the Earth has now left its natural geological epoch, the present interglacial state called the Holocene. Human activities have become so pervasive and profound that they rival the great forces of Nature and are pushing the Earth into planetary terra incognita. The Earth is rapidly moving into a less biologically diverse, less forested, much warmer, and probably wetter and stormier state.

The phenomenon of global change represents a profound shift in the relationship between humans and the rest of nature. Interest in this fundamental issue has escalated rapidly in the international research community, leading to innovative new research projects like Integrated History and future of People on Earth (IHOPE) (8). The objective of this paper is to explore one aspect of the IHOPE research agenda - the evolution of humans and our societies from hunter-gatherers to a global geophysical force.

To address this objective, we examine the trajectory of the human enterprise through time, from the arrival of humans on Earth through the present and into the next centuries. Our analysis is based on a few critical questions:

- Is the imprint of human activity on the environment discernible at the global scale? How has this imprint evolved through time?

- How does the magnitude and rate of human impact compare with the natural variability of the Earth's environment? Are human effects similar to or greater than the great forces of nature in terms of their influence on Earth System functioning?

- What are the socioeconomic, cultural, political, and technological developments that change the relationship between human societies and the rest of nature and lead to accelerating impacts on the Earth System?

\section{Pre-Anthropocene Events}

Before the advent of agriculture about 10000-12000 years ago, humans lived in small groups as hunter-gatherers. In recent centuries, under the influence of noble savage myths, it was often thought that preagricultural humans lived in idyllic harmony with their environment. Recent research has painted a rather different picture, producing evidence of widespread human impact on the environment through predation and the modification of landscapes, often through use of fire (9). However, as the examples below show, the human imprint on environment may have been discernible at local, regional, and even continental scales, but preindustrial humans did not have the technological or organizational capability to match or dominate the great forces of nature.

The mastery of fire by our ancestors provided humankind with a powerful monopolistic tool unavailable to other species, that put us firmly on the long path towards the Anthropocene. Remnants of charcoal from human hearths indicate that the first use of fire by our bipedal ancestors, belonging to the genus Homo erectus, occurred a couple of million years ago. Use of fire followed the earlier development of stone tool and weapon making, another major step in the trajectory of the human enterprise.

Early humans used the considerable power of fire to their advantage (9). Fire kept dangerous animals at a respectful distance, especially during the night, and helped in hunting protein-rich, more easily digestible food. The diet of our ancestors changed from mainly vegetarian to omnivorous, a shift that led to enhanced physical and mental capabilities. Hominid brain size nearly tripled up to an average volume of about $1300 \mathrm{~cm}^{3}$, and gave humans the largest ratio between brain and body size of any species (10). As a consequence, spoken and then, about 10000 years ago, written language could begin to develop, promoting communication and transfer of knowledge within and between generations of humans, efficient accumulation of knowledge, and social learning over many thousands of years in an impressive catalytic process, involving many human brains and their discoveries and innovations. This power is minimal in other species.

Among the earliest impacts of humans on the Earth's biota are the late Pleistocene megafauna extinctions, a wave of extinctions during the last ice age extending from the woolly mammoth in northern Eurasia to giant wombats in Australia (11-13). A similar wave of extinctions was observed later in the Americas. Although there has been vigorous debate about the 
AMBIO (2011) 40:739-761

DOI 10.1007/s13280-011-0185-x

INVITED PAPER

\title{
The Anthropocene: From Global Change to Planetary Stewardship
}

\author{
Will Steffen, Åsa Persson, Lisa Deutsch, Jan Zalasiewicz, Mark Williams, Katherine Richardson, \\ Carole Crumley, Paul Crutzen, Carl Folke, Line Gordon, Mario Molina, Veerabhadran Ramanathan, \\ Johan Rockström, Marten Scheffer, Hans Joachim Schellnhuber, Uno Svedin
}

Received: 29 June 2011/Accepted: 29 June 2011/Published online: 12 October 2011

\begin{abstract}
Over the past century, the total material wealth of humanity has been enhanced. However, in the twentyfirst century, we face scarcity in critical resources, the degradation of ecosystem services, and the erosion of the planet's capability to absorb our wastes. Equity issues remain stubbornly difficult to solve. This situation is novel in its speed, its global scale and its threat to the resilience of the Earth System. The advent of the Anthropence, the time interval in which human activities now rival global geophysical processes, suggests that we need to fundamentally alter our relationship with the planet we inhabit. Many approaches could be adopted, ranging from geoengineering solutions that purposefully manipulate parts of the Earth System to becoming active stewards of our own life support system. The Anthropocene is a reminder that the Holocene, during which complex human societies have developed, has been a stable, accommodating environment and is the only state of the Earth System that we know for sure can support contemporary society. The need to achieve effective planetary stewardship is urgent. As we go further into the Anthropocene, we risk driving the Earth System onto a trajectory toward more hostile states from which we cannot easily return.
\end{abstract}

Keywords Earth System - Anthropocence . Planetary stewardship - Ecosystem services - Resilience

\section{PEOPLE AND THE PLANET: HUMANITY AT A CROSSROADS IN THE TWENTY-FIRST CENTURY}

The twin challenges of "peak oil"-decreasing petroleum resources and increasing demand - and climate change are redefining the pathways of human development in the twenty-first century (Sorrell et al. 2009; ASPO 2010; Richardson et al. 2011). Less well known is the potential shortage of the mineral phosphorus and the increasing competition for land-sometimes referred to as the "land grab" in relation to Africa-as the new economic giants of Asia move to secure food resources in non-Asian territories. The pathways of development followed by today's wealthy countries after the Second World War-built on plentiful, cheap fossil fuel energy resources, an abundance of other material resources, and large expanses of productive land to be developed-cannot be followed by the $75-80 \%$ of the human population who are now at various stages of their trajectories out of poverty, and are beginning to compete with today's wealthy countries for increasingly scarce resources.

A large fraction of our population of nearly 7000 million people needs more access to food, water and energy to improve their material standard of living, and the prospect of an additional 2000 million by 2050 intensifies the need for basic resources. These challenges come at a time when the global environment shows clear signs of deterioration and, as a consequence, questions the continuing ability of the planet to provide the same accommodating environment that has facilitated human development over the past 10000 years.

Climate change is a prominent sign of human-driven changes to the global environment. The evidence that the Earth is warming is unequivocal, and human emissions of greenhouse gases, most importantly carbon dioxide $\left(\mathrm{CO}_{2}\right)$, have been responsible for most of the warming since the middle of the twentieth century (IPCC 2007). The manmade greenhouse gases have already trapped enough infrared energy to warm the planet by more than $2^{\circ} \mathrm{C}$ (Ramanathan and Feng 2008). Although many uncertainties still surround the risks associated with climate change, 